\title{
Characterization of Extracellular Polymeric Substance (EPS) from Cladophora Glomerata under Different Culture Salinities
}

\author{
Yi-Chao Lee, Hwey-Lin Sheu, and Shui-Ping Chang
}

\begin{abstract}
Cladophora glomerata is the most abundant algae in freshwater throughout the world. This study discovered that changing culture salinity can induce $C$. glomerata to produce massive amounts of EPS. Comparing the contents and characteristic functional groups of the EPS under different culture salinity conditions. The contents of protein (2.15-2.71 $\left.\mathrm{mg} \mathrm{g}^{-1}\right)$ and polysaccharide (6.94-12.64 $\left.\mathrm{mg} \mathrm{g}^{-1}\right)$ variable increased with increased culture salinity; the ratios if protein to polysaccharide decreased with the increased culture salinity. The FTIR spectra analysis suggested that protein (1640-1680 $\left.\mathrm{cm}^{-1}\right)$ and polysaccharide $\left(1120-1170 \mathrm{~cm}^{-1}\right)$ were the major components in EPS. Therefore, the range of contents in EPS and the ratios of protein to polysaccharide are influenced by culture salinity obviously.
\end{abstract}

Index Terms-Cladophora glomerata, algae, extracellular polymeric substances (EPS), protein, polysaccharide.

\section{INTRODUCTION}

C. glomerata (Chlorophyta, Cladophoraceae) is a euryhaline algae; the abundant species can survive in estuaries or lagoons of variable salinity [1]. To adapt to different salinities, Cladophora can change its total lipids as well as the composition of the lipids [2]. As recent research has shown, the EPS of the algae are highly sensitive to salinity. The salinity of the growing environment is increased, C. glomerata starts to secrete massive EPS that a mucilage layer is formed outside of the cell wall. In recent years, interest in the exploitation of valuable EPSs have been studied and used as renewable natural resources for wide spectrum of applications, including nutraceuticals, pharmaceuticals /cosmetics, food, and so on [3], [4].Algae can grow in the different environment and EPS production which make algae a perfect candidate for renewable and sustainable biomaterial exploration.

This study investigated EPS production and the levels of its primary major componets of polysaccharide and protein under different salinity by exploring the features of $C$. glomerata. This study also indetified the functional groups of EPS that wrere extracted from algae under different salinity, and hopefully the study results can be used as a reference for valuable EPS exploration.

Manuscript received April 9, 2019; revised June 12, 2019

The authors are with the Department of Environmental Engineering Kun Shan University, No.195, Kunda Rd., YongKang Dist., Tainan City 710-03, Taiwan (e-mail: lyc007@mail.ksu.edu.tw, sheu@mail.ksu.edu.tw, spchang@mail.ksu.edu.tw).

\section{MATERIALS AND METHODS}

\section{A. Algae}

Cladophora is a branched and filamentous algae, the cell walls of which comprise an inner layer of cellulose, a middle layer of pectin, and an outer layer of chitin. In fresh water. The surface of the algae is rougher, hosting a number of epiphytes, primarily Bacillariophyta as well as Cladophora, Cyanophyta, and Euglenophyta. C. glomerata usually is the dominant species in its habitat. In Taiwan, the dry weight of algae from freshwater rivers per square meters was up to $117 \mathrm{~g} / \mathrm{m}^{2}$. The algae that were used in this study, the species $C$. glomerata were collected from a main river in southernTaiwan, the upstream of the Zengwun River $\left(23^{\circ} 04^{\prime} \mathrm{N}, 120^{\circ} 04^{\prime} \mathrm{E}\right)$, and then transferred to aquariums with different salinities for further culturing.

\section{B. Influence of Salinity on C.glomerata EPS}

The sessile $C$. glomerata grew healthily on the carriers (pebbles) and was harvested from the upstream of the Zengwun River in southern Taiwan. The river water above the tidal river reaches was also brought back to the laboratory to prepare a culture medium with different concentrations of salinity, including 5 different salinities such as unadjusted (assuming it was $0.0 \%$ ), $3.0 \%$, $10.0 \%$ o, 20.0\%o, and 30.0\%o. Individual aquariums contained 10 liters of river water with different salinities, and the water was circulated using a small motor to create an adequate environment in which to culture C. glomerata. Samples were then taken at $48 \mathrm{~h}$ after treated.

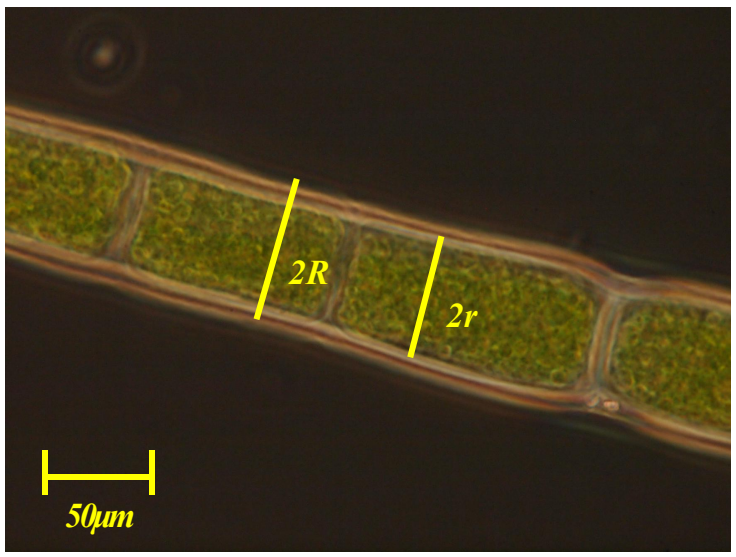

Fig. 1. Illustration of how the measurement of mucilage layer.(the thickness of mucilage layer $=\mathrm{R}-\mathrm{r}$, scale bar $=50 \mu \mathrm{m}$ ).

\section{Thickness of Extracellular Mucilage Layer}

To measure the mucilage layer to determine the EPS, we 
employed the methods used by Tien et al. (2002) [5] and Chiou et al. (2010) [6]. Fig. 1 shows measurements of the mucilage layer of the algae. Algae samples were placed on glass slides with an appropriate quantity of India ink and then observed using an optical microscope. The green regions in the image are the cell walls of Cladophora; the uniform halo on the outside was used to estimate the thickness of the mucilage layer.

\section{EPS Extraction and Analysis}

The ultrasonication method was used for the EPS extraction [7]. The algae was harvested from the aquarium, washed twice with tap water, and drained in a strainer at room temperature for $2 \mathrm{~h}$ until it dried naturally. Afterward extraction procedures were started (as indicated in Fig. 1). All chemicals used in this work were of analytical grade. Polysaccharide content was determined by the phenol-sulfuric acid using glucose as a standard [8]. Protein content was determined according to Bradford (1976) with bovine serum albumin BSA, Sigma A2153 100mg/ml [9]. The total EPS content was measured as the sum of these two substances.

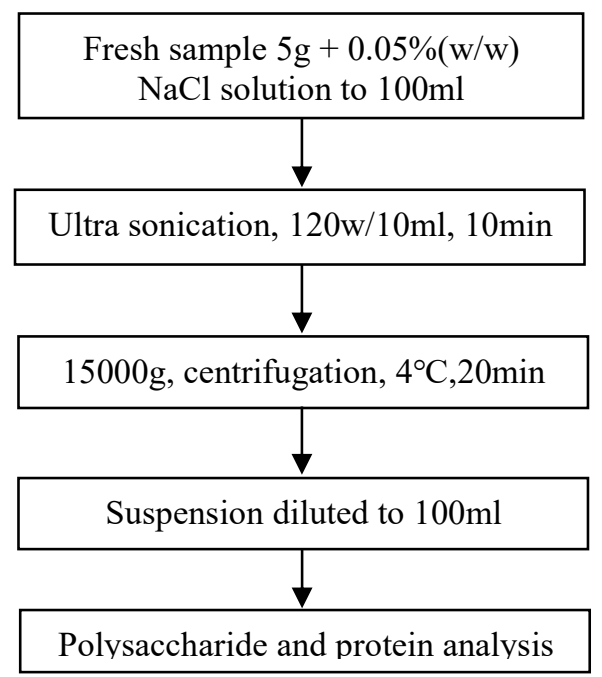

Fig. 2. Procedure for the EPS extraction process for $C$. glomera.

\section{E. FT-IR Spestroscopy Analysis}

FT-IR spectroscopy (Spectrum Gx) was used to detect vibraction method. Spectra were scanned from 4,000 400 $\mathrm{cm}^{-1}$. The spectra were baseline corrected and normalized to 1.0 before tests.

\section{RESULTS AND DISCUSSION}

\section{A. The Influence of Salinity on the C. Glomerata} Mucilage Layer

To determine the influence of variations in salinity on the EPS and epiphytes of $C$. glomerata, we conducted experiments using onsite river water and various concentrations of $\mathrm{NaCl},(0.0 \%$ o $3.0 \%$ o, $5.0 \%$, $10.0 \%$, $20.0 \%$ o and $30.0 \%$ salinity) to cultivate well-grown Cladophora algae samples.

Table I and Fig. 3 demonstrate the changes of C. glomerata EPS amounts under culture conditions with different salinity.
The results indicated that the culture salinity increased ( $\geqq$ $3.0 \%$ ), EPS secretion also greatly increased accordingly. In this case, $C$. glomerata, which grows naturally in freshwater areas and thus hardly forms a mucilage layer outside of its cell walls, may start to formulate mucilage layers in accordance with the increase in salinity. To protect itself, the algae could change its physiological conditions to adapt to the environmental changes. But the study results implied that critical salinity for creating significant changes in EPS production was $3.0 \%$.

TABLE I: CHANges of THE THiCKNeSS OF MuCILAge LAYER IN DifFerent SALINITY

\begin{tabular}{crrrrrrr}
\hline \multirow{2}{*}{ salinity } & \multicolumn{7}{c}{ Sample No. } \\
\cline { 2 - 8 } & \multicolumn{1}{c}{1} & \multicolumn{1}{c}{3} & \multicolumn{1}{c}{4} & \multicolumn{1}{c}{5} & \multicolumn{1}{c}{6} & Mean \\
\cline { 2 - 8 } $1(0 \%)$ & 7.14 & 6.46 & 7.48 & 7.34 & 6.12 & 5.78 & 6.72 \\
$2(3.0 \%)$ & 12.79 & 11.80 & 13.66 & 13.04 & 11.18 & 11.80 & 12.38 \\
$3(10.0 \%)$ & 14.27 & 13.42 & 15.83 & 15.26 & 12.72 & 12.01 & 13.92 \\
$4(20.0 \%)$ & 14.04 & 13.30 & 15.52 & 15.52 & 12.56 & 13.15 & 14.01 \\
$5(30.0 \%)$ & 16.58 & 15.01 & 17.37 & 17.06 & 14.22 & 13.43 & 15.61 \\
\hline
\end{tabular}

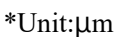

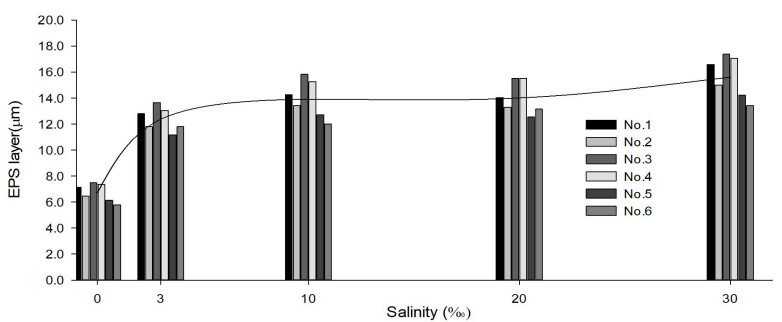

Fig. 3. Changes of the thickness of mucilage.

TABLE II: Polysaccharide LeVEl UNDER DifFERENT Culture SALINITY

\begin{tabular}{cccccccc}
\hline & \multicolumn{7}{c}{ Sample No. } \\
\cline { 2 - 8 } Salinity & 1 & 2 & 3 & 4 & 5 & 6 & Mean \pm SD \\
\cline { 2 - 8 } $1(0 \%)$ & 7.02 & 7.09 & 6.84 & 7.08 & 7.04 & 6.81 & $6.98 \pm 0.12$ \\
$2(3.0 \%)$ & 10.50 & 10.19 & 10.50 & 10.46 & 10.41 & 10.31 & $10.39 \pm 0.12$ \\
$3(10.0 \%)$ & 11.43 & 11.97 & 11.91 & 11.90 & 12.03 & 11.37 & $11.77 \pm 0.29$ \\
$4(20.0 \%)$ & 12.25 & 12.37 & 12.50 & 12.51 & 12.32 & 12.24 & $12.37 \pm 0.12$ \\
$5(30.0 \%)$ & 12.52 & 12.90 & 12.77 & 12.90 & 12.87 & 12.44 & $12.73 \pm 0.21$ \\
\hline
\end{tabular}

Unit:mg g-1 fresh algae

TABLE III: PROTIEN LEVEL UNDER DIFFERENT CULTURE SALINITY

\begin{tabular}{cccccccc}
\hline & \multicolumn{8}{c}{ Salinity } & \multicolumn{1}{c}{ Sample No. } \\
\cline { 2 - 8 } $1(0 \%)$ & 2.17 & 2.20 & 2.13 & 2.20 & 2.20 & 2.11 & $2.17 \pm 0.04$ \\
$2(3.0 \%)$ & 2.73 & 2.76 & 2.68 & 2.78 & 2.81 & 2.59 & $2.73 \pm 0.08$ \\
$3(10.0 \%)$ & 2.74 & 2.77 & 2.68 & 2.79 & 2.69 & 2.72 & $2.73 \pm 0.04$ \\
$4(20.0 \%)$ & 2.70 & 2.74 & 2.64 & 2.67 & 2.77 & 2.69 & $2.70 \pm 0.05$ \\
$5(30.0 \%)$ & 2.68 & 2.71 & 2.63 & 2.64 & 2.68 & 2.68 & $2.67 \pm 0.03$ \\
\hline & & & & \multicolumn{5}{c}{ Unit:mg $\mathrm{g}^{-1}$ fresh algae }
\end{tabular}

In this study, we discovered that on C. glomerata, an increase in salinity can accelerate the secretion of EPS, which thickens the extracellular mucilage layer, thereby affecting the attachment of epiphytic algae also. 


\section{B. The Influence of Different Salinity on the Level of} Polysaccharide and Protein in EPS of C. Glomerata

The changes in polysaccharides levels in EPS under different salinity are shown in Table II The changes in proteins levels in EPS under different salinity are shown in Table III From the previous results, salinity impacts $C$. glomerata protein. Therefore, changes in salinity may stimulate algae originally grown in freshwater areas into producing massive amount of EPS. And the thickness of mucilage layer is increased in accordance with the increase in salinity.

By exploring the euryhaline feature of $C$. glomerata, this study discovered that mucilage layer could be massively induced by regulating environmental salinity.

\section{The Influence of Salinity on the C. Glomerata EPS}

The total EPS content was measured as the sum of polysacchrides and protein also. Fig. 4 and Table IV shows the change of protein and polysaccharide in the EPS of $C$. glomerata at different salinities. The protein contents increased from 2.15 to $2.71 \mathrm{mg} \mathrm{g}^{-1}$ fresh alage with the increase in the salinity from $0 \%$ to $30 \%$. Similarly the polysaccharide contents also increased from 6.94 to $12.64 \mathrm{mg}$ $\mathrm{g}^{-1}$ fresh alage with the same culture condition. The protein to polysaccharide ratios in EPS decreased from 0.31 to 0.21 with the increase in the salinity from $0 \%$ to $30 \%$. Some studies have reported the increase in salinity could cause microoganisms to produce more exopolysaccharide due to the variation of osmotic pressure between micooganisms and the bulk solution [10], [11].

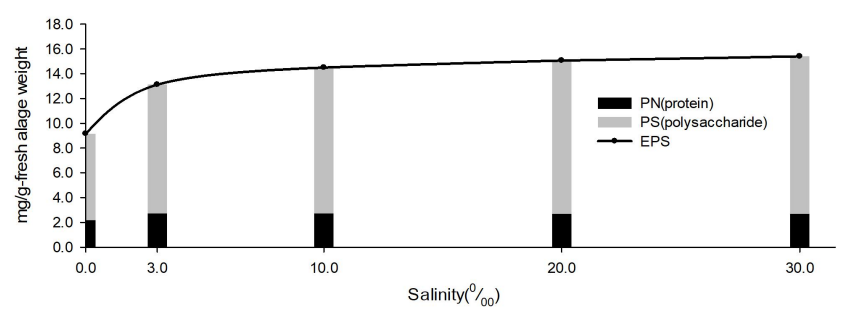

Fig. 4. Variation of EPS extracted from C. glomerata under different culture salinity.

TABLE IV: AMOUNTS AND CONTENTS OF EPS EXTRACTED FROM $C$. GLOMERATA UNDER DIFFERENT CULTURE SALINITY

\begin{tabular}{|c|c|c|}
\hline \multirow[b]{2}{*}{ salinity } & \multicolumn{2}{|c|}{ Organic matter contents ( $\mathrm{mg} \mathrm{g}^{-1}$ fresh algae) } \\
\hline & $\begin{array}{c}\text { EPS } \\
\text { (protein }+ \text { polysaccharide) }\end{array}$ & $\begin{array}{c}\text { Protein } \\
\text { /polysaccharide }\end{array}$ \\
\hline $1(0.0 \%)$ & $9.15 \pm 0.158$ & $0.311 \pm 0.001$ \\
\hline $2(3.0 \%)$ & $13.12 \pm 0.152$ & $0.262 \pm 0.008$ \\
\hline $3(10.0 \%)$ & $14.50 \pm 0.290$ & $0.232 \pm 0.007$ \\
\hline $4(20.0 \%$ o) & $15.07 \pm 0.102$ & $0.218 \pm 0.005$ \\
\hline $5(30.0 \%)$ & $15.40 \pm 0.203$ & $0.210 \pm 0.004$ \\
\hline
\end{tabular}

The study discovered that EPS could be massively induce by regulating salinity, and the contents of protein and polysaccharide in EPS can also be controlled using the different salinities of culture condition. and the level of polysaccharide / protein ratio in EPS can also be controlled using the different salinity of habitats when controlling other environmental factors

\section{FT-IR Spestroscopy Analysis}

FTIR spectra of EPS extracted under different salinities are depicted in Fig. 5 The carboxyl and amino groups, a strong and wide waveband appeared around $3347 \mathrm{~cm}^{-1}$ in the range between the $\mathrm{O}-\mathrm{H}$ and carboxylic groups. The peaks appeared at approximately $1647 \mathrm{~cm}^{-1}$ can be attributed to stretch in $\mathrm{C}=\mathrm{N}, \mathrm{C}=\mathrm{C}$ and $\mathrm{C}=\mathrm{O}$ bonds, the bands at $1370-1450$ (stretching vibration of $\mathrm{CH}_{2}$ ) and $1030-1060 \mathrm{~cm}^{-1}$ (stretching vibration of $\mathrm{CO})$ are assigned of polysaccharide [12], [13].

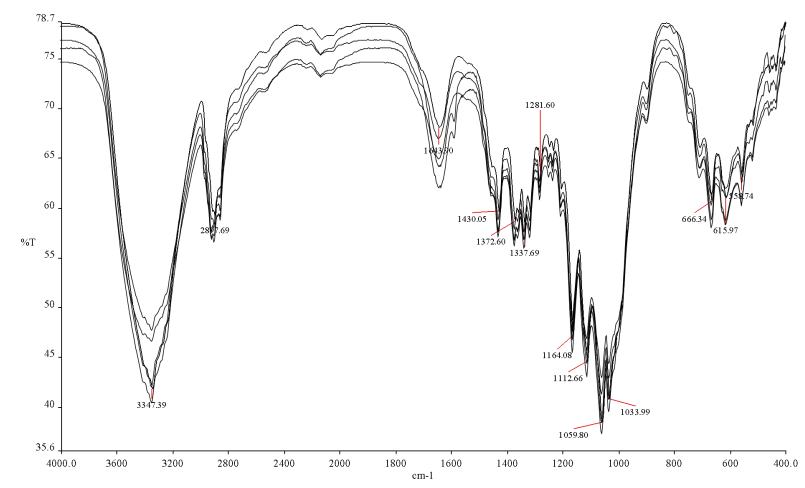

Fig. 5. FTIR spectra of EPS extracted from C. glomerata under different culture salinities.

The peaks appeared at $1372 \mathrm{~cm}^{-1}$ and $1034 \mathrm{~cm}^{-1}$ signify $\mathrm{N}-\mathrm{H}$ bonds, $-\mathrm{CH}_{3}$ wagging and $\mathrm{C}-\mathrm{OH}$ at $666 \mathrm{~cm}^{-1}$ and $619 \mathrm{~cm}^{-1}$ are likely caused by C-N-S scissoring, a phenomenon which can also be found in peptide structures.

Further investigation showed that the EPS extracted from cultured different salinities alage, presented similar absorption bands. Based on the above results, the effects of culture salinity, for EPS extraction yields and ratios of protein to polysaccharide only.

\section{SUMMARY}

This study compared the content and characteristic functional groups of the EPS from the C. glomerata under different culture salinity. The results showed that (1) Thickness of mucilage layer increase with the increase of EPS level. (2) Polysaccharide concentration changed from 6.94 to $12.64 \mathrm{mg} \mathrm{g}^{-1}$, and the protein concentration changed from 2.15 to $-2.71 \mathrm{mg} \mathrm{g}^{-1}$ during the whole tests. (3) Content of protein under all different salinities were found to be lower than polysaccharide. (4) The ratios of protein to polysaccharide decresaed with increased culture salinity. (5) The FTIR spectra analysis suggested that protein (1640-1680 $\left.\mathrm{cm}^{-1}\right)$ and polysaccharide $\left(1120-1170 \mathrm{~cm}^{-1}\right)$ were the major components in EPS. (6) The yield of EPS and fraction EPS contents of algae can controlled by different culture salinity.

\section{REFERENCES}

[1] W. K. Dodds and D. A. Gudder, "The ecology of Cladophora," Journal of Phycology, vol. 28, pp. 415-427, 1992.

[2] Y. Zheng, R. Xiao, and M. Roberts, "Polymer-enhanced enzymatic microalgal cell disruption for lipid and sugar recovery," Algal Res., vol. 14, pp. 100-108, 2016.

[3] Z. Chi, C. D. Su, and W. D. Lu, "A new exopolysaccharide produced by marine Cyanothece sp. 113.," Bioresource Technol., vol. 98, pp. 1329-1332, 2007. 
[4] R. Xiao and Y. Zheng, "Overview of microalgal extracellular polymeric substances (EPS) and their applications," Biotechnology Advances, vol. 34, pp. 1225-1244, 2016.

[5] C. J. Tien, V. Krivtsov, E. Levado, D. C. Sigee, and K. N. White, "Occurrence of cell-associated mucilage and soluble extracellular polisaccharides in Rostherne Mere and their possible significance," Hydrobiologia, vol. 485, no. 1-3, pp. 245-252, 2005.

[6] Y. T. Chiou, M. L. Hsieh, and H. H. Yeh, "Effect of algal extracellular polymer substances on UF membrane fouling," Desalination, vol. 250, pp. 648-652, 2010.

[7] H. Xiaomeng, W. Zhiwei, Z. Chaowei, and Z. Wu, "Effect of ultrasonic power density on extracting loosely bound and tightly bound extracellular polymeric substances," Desalinat., vol. 329, no. 15, pp. $35-40,2013$.

[8] M. Dubois, K. A. Gilles, J. K. Hamilton, P. A. Rebers, and F. Smith, "Colorimetric method for determination of sugars and related substances," Anal. Chem., vol. 28, no. 3, pp. 350-356, 1956.

[9] M. M. Bradford, "A rapid and sensitive method for the quantitation of microgram quantities of protein utilizing the principle of protein-dye binding," Anal. Biochem., vol. 72, pp. 248-254, 1976.

[10] D. T. Spona, "Investigation of extracellular polymer substances (EPS) and physicochemical properties of different activated sludge flocs under steadystateconditions," Enzyme Microb. Technol., vol. 32, pp. $375-385,2003$

[11] A. Mishra, A. Mandoli, and B. Jha, "Physiological characterization and stress-induced metabolic responses of Dunaliella salina isolated from salt pan," J. Ind.Microbiol. Biotechnol., vol. 35, pp. 1093-1101, 2008.

[12] E. Alasonati and V. I. Slaveykova, "Effects of extraction methods on the composition and molar mass distributions of exopolymeric substances of the bacterium Sinorhizobium meliloti," Bioresour Technol., vol. 114, pp. 603-609, 2012.

[13] L. P. Wang, Q. R. Shen, G. H. Yu, W. Ran, and Y. C. Xu, "Fate of biopolymers during rapeseed meal and wheat bran composting as studied by two-dimensional correlation spectroscopy in combination with multiple fluorescence labeling techniques," Bioresour. Technol., vol. 105, pp. 88-94, 2012.

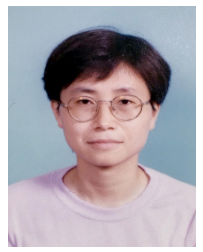

Yi-Chao Lee was born in Taiwan, Chiayi. Her date of birth is 1966/11/14. She is an assistant professor at the Department of Environment Engineering, Kun Shan University in Taiwan, Tainan. She obtained a master's degree in civil engineering from National Chiao Tung University in Taiwan. Her main research areas focus on the environmental engineering.

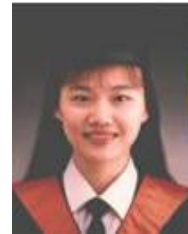

Hwey-Lin Sheu was original born in Taiwan, Nantow. Her date of birth is $1969 / 01 / 03$. She is an associate professor at the Department of Environment Engineering, Kun Shan University in Taiwan, Tainan. She received her Ph.D. degree at National Cheng Kung University in Taiwan. Her main research areas focus on the protection of environment.

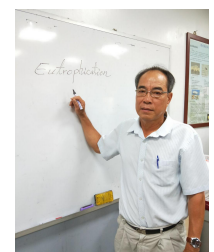

Shui-Ping Chang was born in Taiwan, in 1954. In 1973-1977, he obtained his B.S. in Botany. National Chung Hsing University, Taichung, Taiwan. In 1982-1985, he got his M.S. in environmental science, SUNY at Syrcause, New york, U.S.A. In 1992-1997, he was a Ph.D. of environmental engineering, National Cheng Kung University.

In 1985-1992, he works as a senior engineer and section chief at EPA in Taiwan. From 1997 to present, he is an associate professor at the Department of Environment Engineering, Kun Shan University in Taiwan. His reseach intersits are algae, bioremediation, water treatment 